\title{
Design Optimization of Machining Parameters for AWJ Turning Operations of 718 Inconel Super alloy Based on the Taguchi
}

\begin{tabular}{|cc|}
\hline \multicolumn{1}{|c|}{ Fuat KARTAL*1 } \\
\hline${ }^{1}$ Kastamonu University, Mechanical Engineering Department, 37100 Kastamonu, TURKEY \\
\hline \\
\hline Başvuru/Received: 02/11/2017 $\quad$ Kabul/Accepted: 24/12/2017 $\quad$ Son Versiyon/Final Version: 29/01/2018 \\
\hline
\end{tabular}

\begin{abstract}
Inconel Alloy 718 super alloy was machined using abrasive water jet (AWJ) in this study. Following the cutting process, average surface roughness $(\mathrm{Ra} \mu \mathrm{m})$ and material removal rate (MRR) were investigated and operating parameters were optimized using Taguchi method. Among the machining parameters were pump pressure (PP) $(200,350 \mathrm{MPa})$, nozzle feed rate (NFR) (5, 105 and $205 \mathrm{~mm} / \mathrm{min})$; abrasive flow rate (AFR) (50, 200 and $350 \mathrm{~g} / \mathrm{min})$; spindle speed (SS) (25, 50 and 75 RPM) and standoff distance (SOD) (2, 8 and $14 \mathrm{~mm}$ ). Taguchi L18 (21 x34) orthogonal factorial experiment organization is adopted as experiment design. The effect of parameters on Ra and depth of cut (DoC) was investigated statistically using the outcomes of the variance analysis and S/N rates. As a result of the empirical studies, PP proved to have the highest effect on Ra by $42.35 \%$. On the other hand, NFR proved to have the highest effect on DoC by $72.85 \%$. Increasing SS has improved Ra value while increasing DoC.
\end{abstract}

\section{Keywords}

"Material Removal Rate, Inconel, Taguchi, Surface Roughness and Water Jet Turning" 


\section{INTRODUCTION}

Abrasive water jet (AWJ) is a promising method (Lima et al., 2016, Hasçalık \& Ay, 2013; Ay et al., 2013; Field, 968) for cutting materials as is offers advantages such as absence of thermal influence and a wide area of use including materials with high thickness (Lima et al., 2016, Ay et al., 2013; Taguchi, 1986). It is possible to cut a wider variety of materials using AWJ (Lima et al., 2016) when compared to other conventional cutting methods. Among these, materials are polymers, composites, ornamental rocks, glass, etc. (Kivak et al., 2012, Çaydaş \& Ay, 2016). Many industrial applications today consider abrasive water jet (AWJ) as one of the most promising material processing techniques with a highlight to its versatility. However, the literature provides insufficient information on multiphase flow properties of abrasive water jet at high and ultra-high jet pressures. Fluid dynamics of abrasive water jet has an immediate impact on the processing quality as it directly affects the workpiece and abrasive particles must be considered as one of the contributors to the surface roughness outcome.

Today, many industries adopt AWJ cutting as it allows processing of several types of material with a low thermal influence during the process (Kivak et al., 2012; Çaydaş \& Ay, 2016). The gemstone industry is one of these industries, which increasingly use AWJ as it optimizes the use of material when compared to the conventional cutting methods while being ideal for the industrial needs of cutting flexibility (Kivak et al., 2012; Hasçalık \& Ay, 2013). Surface integrity determines the type of processes to be applied to the workpiece and is an important selection criterion in any kind of machined product. Surface integrity is defined as the changes in the material following the machining process, which may include surface and subsurface alterations in the given material. Peck drilling is one of the important machining processes available in the space industries (Kivak et al., 2012b). Research on the machining of Inconel 718 alloy mostly involves cutting and milling operations while the literature on the abrasive water jet cutting is restricted (Lima et al., 2016; (Lima et al., 2016; Kivak et al., 2012; Ay et al., 2010). Super alloys offer excellent creep strength and tensile strength with better corrosion and oxidation resistance (Kivak, 2012). Among these alloys are iron-based chromium and nickel alloys, iron-nickel, chromium-cobalt alloys, carbide reinforced cobalt based alloys, solid solution reinforced nickel based alloys (Kivak, 2012), deposition and distribution reinforced nickel based alloys (Kivak, 2012, Gür \& Kaya, 2017, Y1ldız et al., 2014). Several new alloys were developed with different operating temperatures in the recent years (Kivak, 2012; Gür \& Kaya, 2017). One of the most important alloys is the Inconel 718 super alloys (Ay et al., 2010). This alloy has a polycrystalline and coaxial microstructure (Kivak, 2012, Gür \& Kaya, 2017). As it offers excellent mechanical properties for low and average temperatures $\left((-250)-(700)^{\circ} \mathrm{C}\right)$ it has recently been increasingly used in space (Kivak, 2012, Y1ldiz et al., 2014), petroleum and nuclear energy industries (Kivak, 2012, Gür \& Kaya, 2017). During the machining process of Inconel 718 (Kivak, 2012), tool temperature easily increases due to the low thermal conductivity of this material. As a result of the higher toughness level of the material, shavings formation proves challenging during the machining process (Ay, 2010; Özay et al., 2016; Savaş et al., 2016). As the manufacturing cost of this material is relatively high, any fault during the machining process may lead to serious monetary losses (Ay et al., 2010; Lima et al., 2016; Bhattacharya et al., 1983; Özay et al., 2016; Savaş et al., 2016).

This study involves longitudinally machining of Inconel Alloy 718 steel with abrasive water jet using machining parameters of NFR, AFR, SS, SOD and PP. The impact of machining parameters on Ra and DoC was investigated. Taguchi method was used for experimental setting and experimental data was analyzed using ANOVA.

\section{MATERIAL AND METHOD}

Materials with a special area of use in the industry, Inconel Alloy 718 of $\varnothing 30 \times 240 \mathrm{~mm}$ in size were used for the experiments. Inconel Alloy 718 is a nickel-chromium alloy, which is prone to precipitation hardening, and it consists of high amounts of iron, niobium, and molybdenum and a small amount of aluminum and titanium. This combination offers higher corrosion resistance and higher strength while being ideal for welding with its excellent weld crack resistance. The alloy provides excellent creep and tensile strength up to $700^{\circ} \mathrm{C}$ (Kivak et al. 2012, Savaş et al., 2016). It is possible to use this alloy for gas turbines, rocket engines, nuclear reactors, pump and tool manufacturing, etc. Chemical composition of the work piece is shown in Table 1, while its mechanical properties are shown in Table 2 (Kivak et al. 2012b).

Table 1. Chemical composition of specimens (weight \%)

\begin{tabular}{c|c|c|c|c|c|c|c|c|c|c}
\hline C & Mn & Si & Cr & Ni & Co & Mo & Nb + Ta & Ti & Al & Fe \\
\hline 0.040 & 0.08 & 0.08 & 18.37 & 53.37 & 0.23 & 3.04 & 5.34 & 0.98 & 0.50 & 17.80 \\
\hline
\end{tabular}


Table 2. Mechanical properties of Inconel Alloy 718

\begin{tabular}{cccc}
\hline Hardness (HB) & Yield limits (MPa) & Tensile stress (MPa) & Elongation \% (5do) \\
\hline 388 & 1375 & 1170 & 23.3 \\
\hline
\end{tabular}

Taguchi method is a well-known technique providing a systematic and efficient approach to process optimization and is a strong tool for high quality systems design (Kivak et al. 2012). In this study, the minimum Ra value will be considered the best performance. Smaller is better S/N characteristic was adopted in the analyses for the smallest value of Ra. On the other hand, larger is better $\mathrm{S} / \mathrm{N}$ function used for the highest material cutting value. $\mathrm{S} / \mathrm{N}$ ratio equations used in the analyses are shown below. First and second equations involve $\eta$ Signal/Noise ratio; yi the experimental measure numbered $i, n$ the number of test.

Smaller is better:

$$
\eta=S /_{N}=-10 \cdot \log \left(\sum \frac{y_{i}^{2}}{n}\right)
$$

Larger is better:

$$
\eta=S /_{N}=-10 \cdot \log \left(\sum \frac{\frac{1}{y_{i}^{2}}}{n}\right)
$$

The acceptable significance level for ANOVA analysis in this study was set at a P value equal to $95 \%(\sigma=0.05)$. Taguchi L18 $(21$ $\mathrm{x} 34$ ) orthogonal array design was generated for the factors (Table 3 and Table 4) in order to be able to see the influences of the parameters and experimental study was performed. Minitab 17 experimental design software was used for experiment setup, optimization and variance analyses. All the experiments involved 120 Mesh Garnet type abrasive material and the nozzle diameter was fixed at $0.75 \mathrm{~mm}$.

Table 3. The parameters used in the AWJT and their levels

\begin{tabular}{llllll}
\hline Code & Parameters & Unit & Level 1 & Level 2 & Level 3 \\
\hline A & Pump pressure & $\mathrm{MPa}$ & 200 & 350 & \\
B & Nozzle feed rate & $\mathrm{mm} / \mathrm{min}$ & 5 & 105 & 205 \\
C & Abrasive flow rate & $\mathrm{g} / \mathrm{min}$ & 50 & 250 & 450 \\
D & Standoff distance & $\mathrm{mm}$ & 2 & 8 & 14 \\
E & Spindle speed & RPM & 25 & 50 & 75 \\
\hline
\end{tabular}

A CNC abrasive water jet lathe with a pump pressure of $415 \mathrm{MPa}$ was used in this study. Surface measurements were conducted using "Mitutoyo" SJ-301 surface roughness measurement device. Only the average surface roughness (Ra) values were taken into consideration during the roughness measurements. Ra values were taken from four points located in the mid part of the work piece. DoC measurements were conducted on the surface of the material using a digital compass following each machining process and difference calculations were conducted using the diameter measurements recorded before the machining process. The parameters used in the volume calculation with regards to the equation 3 are as follows; Di i pre-cutting diameter, Di+1: post-cutting diameter, $\mathrm{h}$ : longitudinal turning distance.

$$
\operatorname{DoC}_{\mathrm{i}}=(D i-D i+1) / 2
$$

This study used a turning lathe setup which operated underwater with a maximum sound level of $85 \mathrm{~dB}$ developed in order to be used in abrasive water jet machining (Figure 1). 

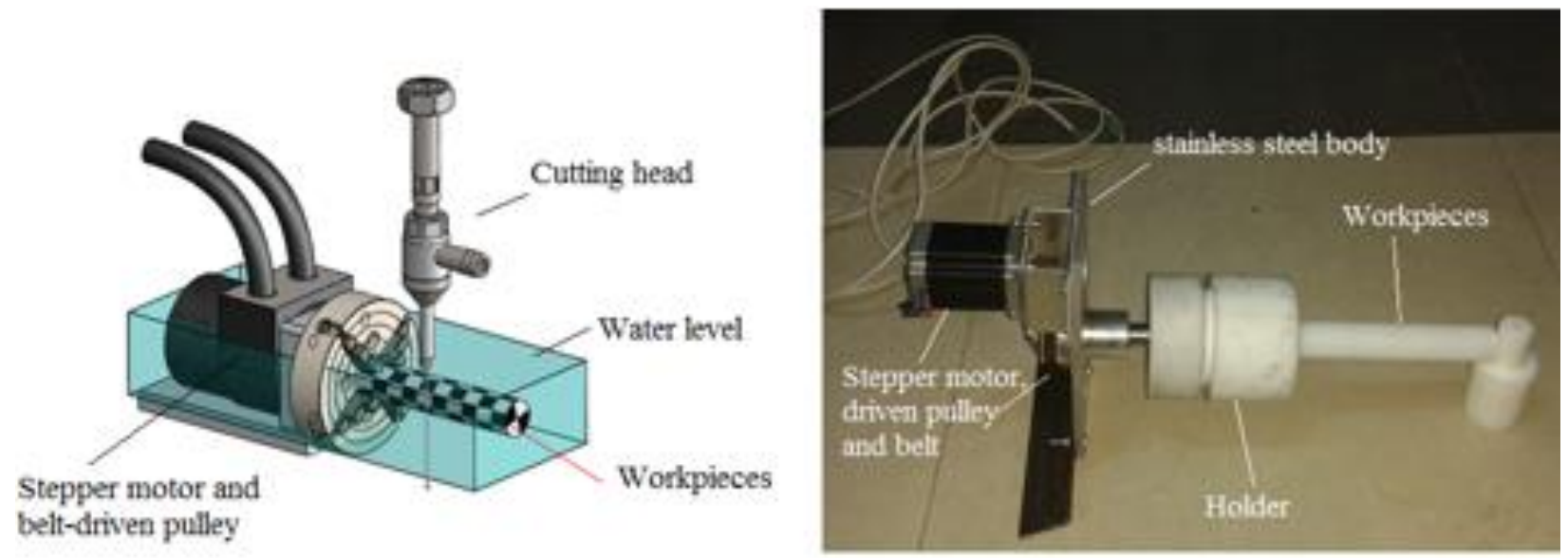

Fig. 1. A schematic and prototype view of the developed turning mechanism.

\section{EXPERIMENTAL RESULTS}

\subsection{Effect of process parameters on the Ra}

Average Ra values obtained from the AWJ process and S/N ratios calculated according to Equation 1 are shown in Table 4 . Average $\mathrm{S} / \mathrm{N}$ ratios calculated for each level of parameters in order to find the optimum parameters are shown in Table 5. The rankings available in Table 5 shows the importance of the impact of that parameter on Ra. PP, NFR, AFR, SS and SOD, respectively, were found to have the highest effect on Ra according to their Rankings. The highest value of S/N ratio obtained for each parameter stands for the best performance result (lowest Ra value). In this respect, the test configuration established for optimum Ra included the following values in accordance with the graphical display of the $\mathrm{S} / \mathrm{N}$ ratios shown in Fig. 2: PP: $350 \mathrm{~mm}$, NFR $5 \mathrm{~mm} / \mathrm{min}$, AFR: $455 \mathrm{~g} / \mathrm{min}$, SOD: $2 \mathrm{~mm}$ and SS: $75 \mathrm{rpm}$.

Table 4. Ra and S/N ratio value according to L18 orthogonal experiment layer

\begin{tabular}{|c|c|c|c|c|c|c|c|}
\hline $\begin{array}{l}\text { EXP. } \\
\text { No }\end{array}$ & $\begin{array}{l}\text { PP } \\
\text { (MPa) }\end{array}$ & $\begin{array}{l}\text { NFR } \\
(\mathrm{mm} / \mathrm{min})\end{array}$ & $\begin{array}{l}\text { AFR } \\
\text { (g/min) }\end{array}$ & $\begin{array}{l}\text { SOD } \\
(\mathrm{mm})\end{array}$ & $\begin{array}{l}\text { SS } \\
(\text { RPM) }\end{array}$ & $\begin{array}{l}\text { Ra } \\
(\mu \mathrm{m})\end{array}$ & $\begin{array}{l}\mathrm{S} / \mathrm{N} \\
\mathrm{dB}\end{array}$ \\
\hline 1 & 200 & 5 & 50 & 2 & 25 & 2,14 & $-6,59$ \\
\hline 2 & 200 & 5 & 250 & 8 & 50 & 1,54 & $-3,72$ \\
\hline 3 & 200 & 5 & 450 & 14 & 75 & 1,82 & $-5,18$ \\
\hline 4 & 200 & 105 & 50 & 2 & 50 & 2,99 & $-9,50$ \\
\hline 5 & 200 & 105 & 250 & 8 & 75 & 2,29 & $-7,18$ \\
\hline 6 & 200 & 105 & 450 & 14 & 25 & 3,03 & $-9,61$ \\
\hline 7 & 200 & 205 & 50 & 8 & 25 & 3,11 & $-9,84$ \\
\hline 8 & 200 & 205 & 250 & 14 & 50 & 2,58 & $-8,22$ \\
\hline 9 & 200 & 205 & 450 & 2 & 75 & 2,02 & $-6,09$ \\
\hline 10 & 350 & 5 & 50 & 14 & 75 & 1,53 & $-3,71$ \\
\hline 11 & 350 & 5 & 250 & 2 & 25 & 1,25 & $-1,91$ \\
\hline 12 & 350 & 5 & 450 & 8 & 50 & 1,06 & $-0,49$ \\
\hline 13 & 350 & 105 & 50 & 8 & 75 & 1,59 & $-4,03$ \\
\hline 14 & 350 & 105 & 250 & 14 & 25 & 1,90 & $-5,56$ \\
\hline 15 & 350 & 105 & 450 & 2 & 50 & 1,34 & $-2,57$ \\
\hline
\end{tabular}




\begin{tabular}{ccccccccc}
\hline 16 & 350 & 205 & 50 & 14 & 50 & 2,26 & $-7,08$ & \\
17 & 350 & 205 & 250 & 2 & 75 & 1,40 & $-2,90$ \\
18 & 350 & 205 & 450 & 8 & 25 & 1,76 & $-4,91$ \\
\hline
\end{tabular}

Table 2. Mechanical properties of Inconel Alloy 718.

\begin{tabular}{|c|c|c|c|}
\hline Hardness (HB) & Yield limits (MPa) & Tensile stress (MPa) & Elongation \% (5do) \\
\hline 388 & 1375 & 1170 & 23.3 \\
\hline
\end{tabular}

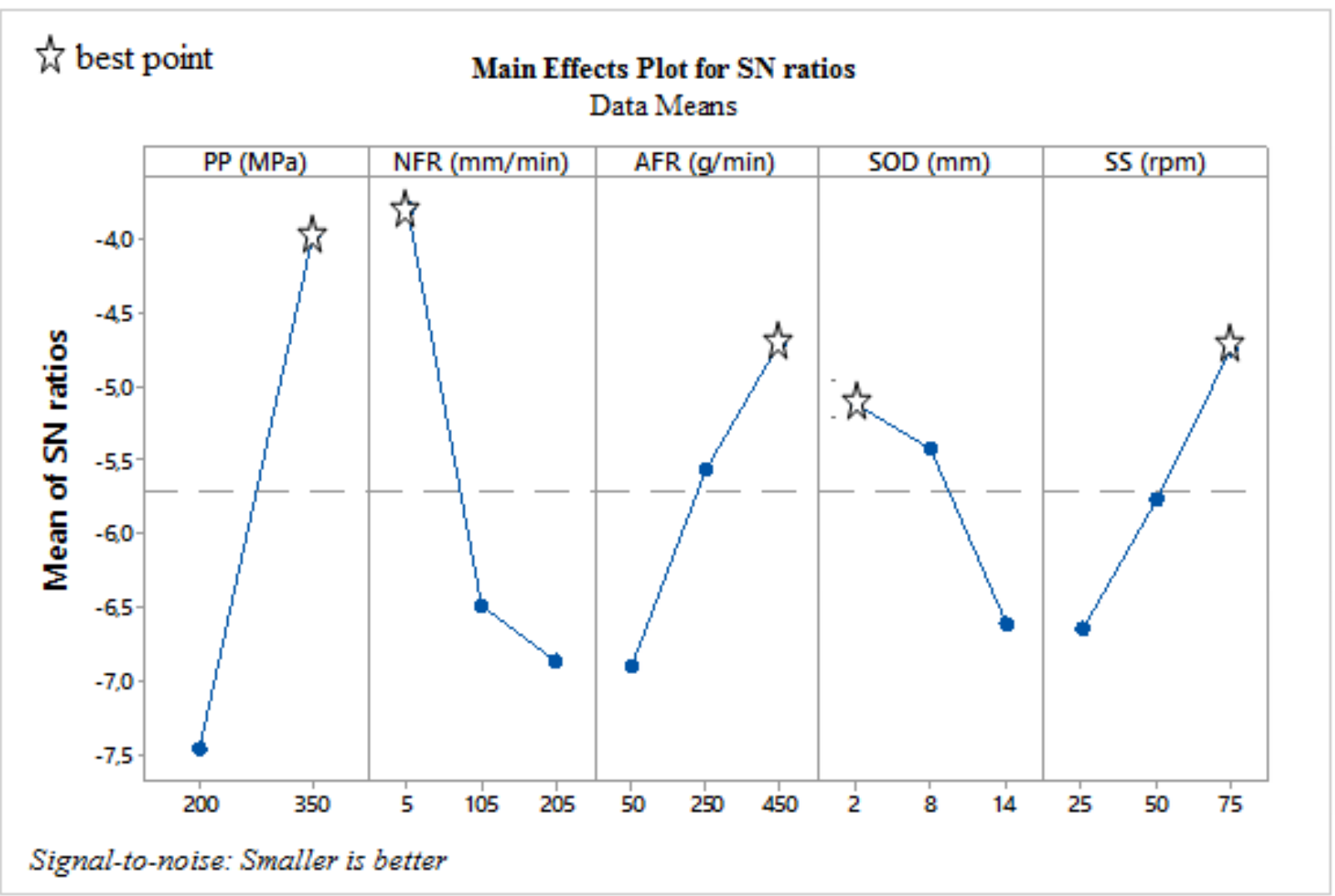

Fig. 2. A Main effects plot for the Ra.

Influence levels of the parameters on Ra are evaluated using ANOVA analysis and the results are shown in Table 6. PP is found to be the most effective factor on Ra by $42.37 \%$ as shown in the percentages available in ANOVA Table. The second most effective factor, on the other hand, was NFR (26.16\%). A growing number of spiral trails on the work piece as NFR was increased resulted in increased Ra value.

Table 6. ANOVA analysis for the Ra

\begin{tabular}{llll}
\hline Hardness (HB) & Yield limits (MPa) & Tensile stress (MPa) & Elongation \% (5do) \\
\hline 388 & 1375 & 1170 & 23.3 \\
\hline
\end{tabular}

The second parameter following NFR, which has an impact on Ra was AFR (11.38\%). It was found that the average surface roughness is directly proportional to AFR and that increasing AFR provides a more homogeneous and more rigid cutting tool with abrasive water jet obtained. 


\subsection{Effect of process parameters on the DoC}

DoC measurement results of the machined surfaces tested in the experimental combinations developed according to the L18 experiment setup and $\mathrm{S} / \mathrm{N}$ ratios calculated according to Equation 2 are shown in Table 7. Average S/N ratios calculated for each level of parameters are shown in Table 8. NFR, AFR, and SS, respectively, were found to have the highest effect on DoC according to their Rankings available in Table 8. Accordingly, the test configuration established for maximum DoC included the following values in accordance with the graphical display of the S/N ratios shown in Fig. 4 . SOD: 14 mm, NFR: 5 mm/min, AFR: 450 g/min, SS: 75 RPM and PP: 350 MPa.

Table 7. DoC and $\mathrm{S} / \mathrm{N}$ ratio according to test results

\begin{tabular}{llllllll}
\hline $\mathbf{E x p}$ & $\mathbf{P P}$ & $\mathbf{N F R}$ & $\mathbf{A F R}$ & $\mathbf{S O D}$ & $\mathbf{S S}$ & $\mathbf{D o C}$ & $\mathbf{S} / \mathbf{N}$ \\
$\mathbf{N o}$ & $(\mathbf{m m})$ & $(\mathbf{m m} / \mathbf{m i n})$ & $(\mathbf{g} / \mathbf{m i n})$ & $(\mathbf{m m})$ & $(\mathbf{R P M})$ & $(\mathbf{m m})$ & $(\mathbf{d B})$ \\
\hline 1 & 200 & 5 & 50 & 2 & 25 & 1,59 & 4,03 \\
2 & 200 & 5 & 250 & 8 & 50 & 2,2 & 6,85 \\
3 & 200 & 5 & 450 & 14 & 75 & 2,88 & 9,20 \\
4 & 200 & 105 & 50 & 2 & 50 & 1,15 & 1,20 \\
5 & 200 & 105 & 250 & 8 & 75 & 1,53 & 3,69 \\
6 & 200 & 105 & 450 & 14 & 25 & 1,6 & 4,07 \\
7 & 200 & 205 & 50 & 8 & 25 & 0,2 & $-14,04$ \\
8 & 200 & 205 & 250 & 14 & 50 & 0,52 & $-5,68$ \\
9 & 200 & 205 & 450 & 2 & 75 & 0,84 & $-1,56$ \\
10 & 350 & 5 & 50 & 14 & 75 & 2,02 & 6,12 \\
11 & 350 & 5 & 250 & 2 & 25 & 2,19 & 6,81 \\
12 & 350 & 5 & 450 & 8 & 50 & 2,58 & 8,24 \\
13 & 350 & 105 & 50 & 8 & 75 & 1,21 & 1,68 \\
14 & 350 & 105 & 250 & 14 & 25 & 1,45 & 3,24 \\
15 & 350 & 105 & 450 & 2 & 50 & 1,79 & 5,03 \\
16 & 350 & 205 & 50 & 14 & 50 & 0,32 & $-10,00$ \\
17 & 350 & 205 & 250 & 2 & 75 & 0,77 & $-2,23$ \\
18 & 350 & 205 & 450 & 8 & 25 & 0,75 & $-2,47$ \\
\hline
\end{tabular}

Table 8. Mean SN ratio for the DoC

\begin{tabular}{llllll}
\hline Level & PP (MPa) & NFR (mm/min) & AFR (g/min) & SOD (mm) & SS (rpm) \\
\hline $\mathbf{1}$ & 1,2035 & 7,013 & $-1,8262$ & 1,27 & 0,3159 \\
$\mathbf{2}$ & 1,6626 & 2,7811 & 1,9855 & 1,4831 & 1,4322 \\
$\mathbf{3}$ & & $-5,4949$ & 4,1399 & 1,546 & 2,5511 \\
Delta & 0,4592 & 12,5079 & 5,9661 & 0,276 & 2,2352 \\
Rank & 4 & 1 & 2 & 5 & 3 \\
\hline
\end{tabular}




\section{best point}

\section{Main Effects Plot for SN ratios} Data Means

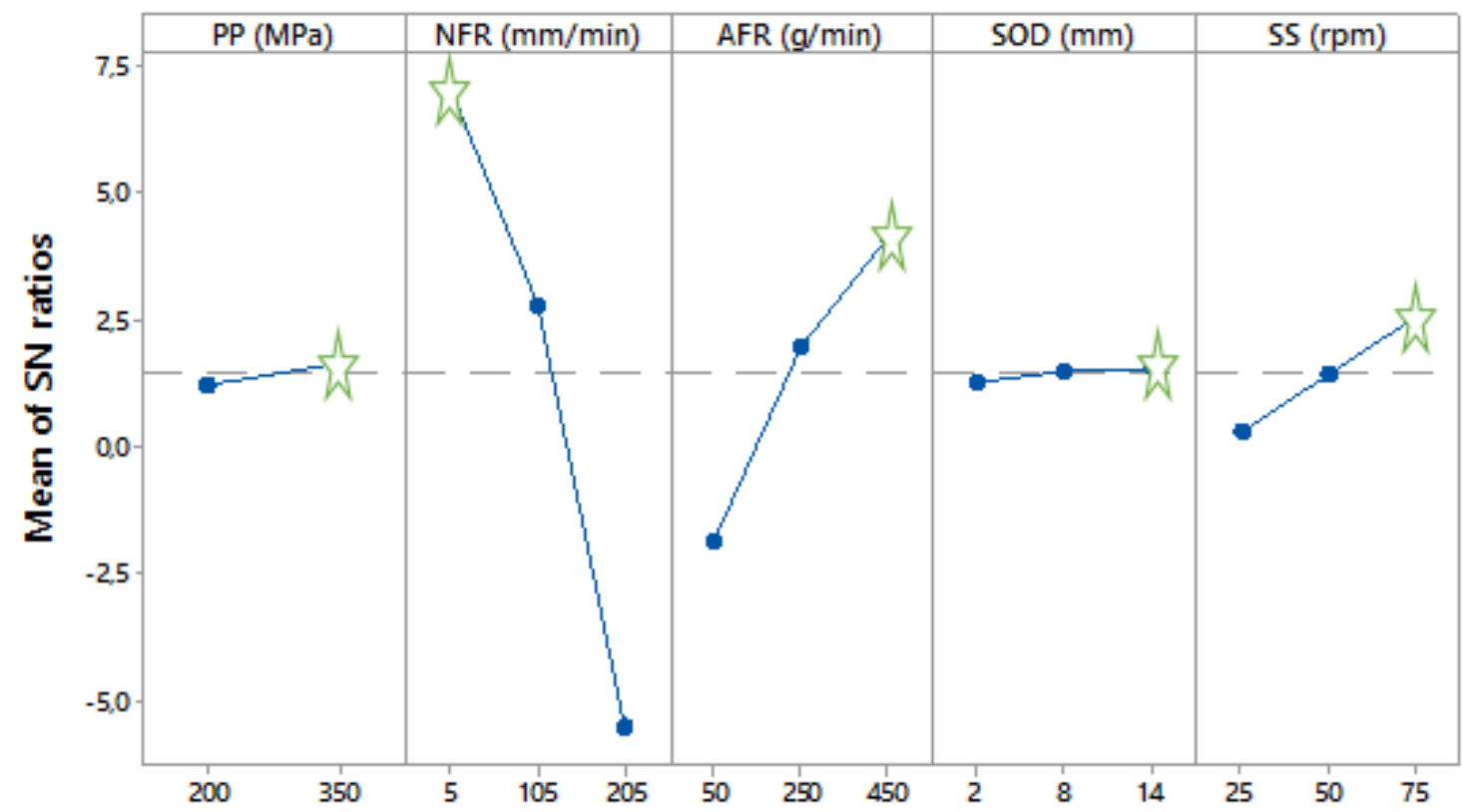

Signal-to-noise: Larger is better

Fig. 2. The main effects of the parameters on the DoC

Influence levels of the parameters on DoC are evaluated using ANOVA analysis and the results are shown in Table 9. NFR is found to be the most effective factor on DoC by $72.85 \%$ as shown in the percentages available in ANOVA Table. Erosion is increased and therefore DoC value is increased when the AFR is increased. The results obtained are compatible with the literature (Ansari \& Hashish, 1995). In their study, Hashish and Ansari reported that increasing AFR also increases the DoC value (Escobar et al., 2012). The parameter of SS, whether it has a rather low effect on DoC by $2.25 \%$, has a significant effect according to its pvalue. The effect of erosion caused by the abrasive jet contacting the surface of the work piece increases with the increasing spindle speed. Thus, increasing spindle speed also increases DoC value. DoC value is an important manufacturing parameter in terms of reduced production time and reduced operating costs. While the material removal process using classic turning methods involves several passes, AWJ turning process is able to remove material in a single pass. Therefore, it is possible to reduce the machining time and operation costs with an economic material removal process when the DoC value is increased. The results obtained are compatible with the literature (Kartal, 2016).

Table 9. ANOVA table for the DoC

\begin{tabular}{lllllll}
\hline Source & DF & Seq SS & Adj SS & Adj MS & F & \% effect \\
\hline PP (MPa) & 1 & 8,54 & 8,54 & 8,54 & 2,61 & 0,14 \\
NFR (mm/min) & 2 & 4371,26 & 4371,26 & 2185,63 & 667,78 & 72,85 \\
AFR (g/min) & 2 & 985,77 & 985,77 & 492,89 & 150,59 & 16,43 \\
SOD (mm) & 2 & 2,26 & 2,26 & 1,13 & 0,35 & 0,04 \\
SS (rpm) & 2 & 134,9 & 134,9 & 67,45 & 20,61 & 2,25 \\
Residual Error & 152 & 497,49 & 497,49 & 3,27 & & 8,29 \\
Total & 161 & 6000,22 & & & & 100,00 \\
\hline
\end{tabular}




\subsection{Confirmation Experiments}

The $\mathrm{Ra}$ and DoC values obtained as a result of the confirmation tests on the estimated optimal conditions and values obtained after calculations are shown (Table10 and 11) and the confirmation tests available consists of the comparisons between the results obtained from the experimental and calculated values. Calculated according to the Taguchi optimization method the values of the control factors of the cutting process with AWJ are as follows: Ra: 0,65 $\mu \mathrm{m}, \mathrm{S} / \mathrm{N}$ ratio: $-0.517795 \mathrm{~dB}$, estimated DoC value: 2.76 $\mathrm{mm}$ and the $\mathrm{S} / \mathrm{N}$ ratio of this value: $11.1804 \mathrm{~dB}$ It was found that experimental and estimated values for Ra and DoC are quite similar.

Table 10. Confirmation results for $\mathrm{Ra}(\mu \mathrm{m})$

\begin{tabular}{|l|l|l|l|l|}
\hline $\begin{array}{l}\text { PP } \\
(\mathbf{M P a})\end{array}$ & $\begin{array}{l}\text { NFR } \\
(\mathbf{m m} / \mathbf{m i n})\end{array}$ & $\begin{array}{l}\text { AFR } \\
(\mathbf{g} / \mathbf{m i n})\end{array}$ & $\begin{array}{l}\text { SOD } \\
(\mathbf{m m})\end{array}$ & $\begin{array}{l}\text { SS } \\
(\mathbf{r p m})\end{array}$ \\
\hline 350 & 5 & 450 & 2 & 75 \\
\hline & & $\begin{array}{l}\text { Estimated } \\
\mathbf{R a}(\boldsymbol{\mu m})\end{array}$ & $\begin{array}{l}\text { Experimental } \\
\mathbf{R a}(\boldsymbol{\mu m})\end{array}$ & $(\%)$ Difference \\
\hline & & 0,65 & 0,79 & 13,50 \\
\hline
\end{tabular}

Table 11. Confirmation results for DoC (mm)

\begin{tabular}{|l|l|l|l|l|}
\hline $\begin{array}{l}\text { PP } \\
(\mathbf{M P a})\end{array}$ & $\begin{array}{l}\text { NFR } \\
(\mathbf{m m} / \mathbf{m i n})\end{array}$ & $\begin{array}{l}\text { AFR } \\
(\mathbf{g} / \mathbf{m i n})\end{array}$ & $\begin{array}{l}\text { SOD } \\
(\mathbf{m m})\end{array}$ & $\begin{array}{l}\text { SS } \\
(\mathbf{r p m})\end{array}$ \\
\hline 350 & 5 & 450 & 14 & 75 \\
\hline & & $\begin{array}{l}\text { Estimated } \\
\text { DoC }(\mathbf{m m})\end{array}$ & $\begin{array}{l}\text { Experimental } \\
\text { DoC }(\mathbf{m m})\end{array}$ & $(\%)$ Difference \\
\hline & & 2,76 & 2,89 & 13,32 \\
\hline
\end{tabular}

\section{CONCLUSIONS}

The Findings of this study are summarized as follows:

All of these parameters were found to be statistically significant for the machinability of Inconel Alloy 718 using AWJ (all pvalues < 0.05).PP is found to be the most effective factor on Ra $(42,37 \%)$ which is followed by NFR (\% 26.16) and AFR (\% $11.38)$ as shown in the percentages available in ANOVA Table. NFR is found to be the most effective factor on DoC (72.85\%) which is followed by AFR (\% 16.43) and SS (\% 2.25) as shown in the percentages available in ANOVA Table. R2 values for Ra and $\mathrm{DoC}$ were calculated to be $96.8 \%$ and $96.1 \%$, respectively. High level of material removal is possible with the AWJT process in a single pass without any production defects. This method is advantageous when compared to classical methods in terms of machining duration. It was possible to observe the level of effects of parameters and their results since the parameters selected was tested for low, medium and high levels. The difference between calculated and estimated Ra was found to be $13.50 \%$, while the difference between calculated and estimated DoC was found to be $13.32 \%$. It was found that Inconel Alloy 718 can be machined using AWJT as it is the case with conventional machining.

\section{References}

Ansari, A. I., \& Hashish, M. (1995). Effect of abrasive waterjet parameters on volume removal trends in turning. Journal of engineering for industry, 117(4), 475-484.

Ay, M., Çaydaş, U., \& Hascalik, A. (2010). Effect of traverse speed on abrasive waterjet machining of age hardened Inconel 718 nickel-based super alloys. Materials and Manufacturing Processes, 25(10), 1160-1165. 
Ay, M., Çaydaş, U., Hasçalık, A., (2013). Optimization of micro EDM drilling of inconel 718 superalloy. The International Journal of Advanced Manufacturing Technology, 66(5-8),1015-1023.

Bhattacharya, S.K., Javaid, A., Lewis, M.H., Walbank, J. (1983). Wear Mechanisms of Syalon Ceramic Tools when Machining Nickel-Based Materials, Metals Technology, 10: 482-483.

Bradley, E. (1988) Super alloys A Technical Guide, ASM Internatıonal, USA, 1-29.

Çaydaş, U., Ay, M., (2016). WEDM cutting of Inconel 718 nickel based superalloy effects of cutting parameters on the cutting quality. Materiali in tehnologije, 50(1),117-125.

E. Lima, C. E. D. A., Lebrón, R., de Souza, A. J., Ferreira, N. F., \& Neis, P. D. (2016). Study of influence of traverse speed and abrasive mass flowrate in abrasive water jet machining of gemstones. The International Journal of Advanced Manufacturing Technology, 83(1-4), 77-87.

Escobar-Palafox, G. A., R. S. Gault, and K. Ridgway. (2012). Characterization of abrasive water-jet process for pocket milling in Inconel 718. Procedia CIRP 1: 404-408.

Ezugwu, E. O., Wanga, Z. M., Machadop A. R. (1998). The Machinability of Nickel- Based Alloys: A Review, Journal of materials Processing Technology, Volume 86, Issues 1-3, 1-16.

Field, M. (1968). Machining Aerospace Alloy, Iron and Steel Institute, Special Report 94, 151-160,.

Gür, A.K., Kaya, S., (2017). Abrasive wear resistance optimization of three different carbide coatings by the Taguchi method. Materials Testing, 59(5),450-455.

Gür, A.K., Kaya, S., (2017). PTA Kaplamalarda Abrasive Aşınma Davranışının Değerlendirilmesinde Bir Taguchi Yaklaşımı. Firat Üniversitesi Mühendislik Bilimleri Dergisi, 29(2),195-202.

Hasçalık, A., Ay, M., (2013). $\mathrm{CO}_{2}$ laser cut quality of Inconel 718 nickel based superalloy. Optics \& Laser Technology, 48(),554564.

Karabulut, Ş., \& Güllü, A. (2009). Dynamic Chip Breaker Design for Nickel-Base, Inconel 718, Alloy with Coated Carbide Tools Using Negative Angle Tool Holder. In Solid State Phenomena (Vol. 147, pp. 758-763). Trans Tech Publications.

Kartal, F. (2016). A review of the current state of abrasive water-jet turning machining method. The International Journal of Advanced Manufacturing Technology, 1-11.

Kartal, F., \& Gökkaya, H. (2015). Effect of abrasive water jet turning process parameters on surface roughness and material removal rate of AISI 1050 steel. Materials Testing, 57(9), 773-782.

Kivak, T., Habali, K., \& Şeker, U. (2012). The Effect of Cutting Paramaters on The Hole Quality and Tool Wear During The Drilling of Inconel 718. Gazi University Journal of Science, 25(2), 533-540.

Özay, Ç., Ballıkaya, H., Savaş, V., (2016). Application of the Taguchi method to select the optimum cutting parameters for tangential cylindrical grinding of AISI D3 tool steel. Materiali in tehnologije, 50(1),81-87.

Rahman, M., Seah, W.K.H., Teo, T.T., “The Machinability of Inconel 718”, Journal of Materials Processing Technology, 63: 199204 (1997).

Savaş, V., Özay, Ç., Ballıkaya, H., (2016). Experimental investigation of cutting parameters in machining of 100Cr6 with tangential turn milling method. Advances in Manufacturing, 4(1),97-104.

Taguchi, G. (1986). Introduction to quality engineering: designing quality into products and processes.

Yıldı, T., Gür, A.K., Aba, S., (2014). Examination of the Wear Behavior of Cu-Ni/B4Cp Composite by the Taguchi Method. Materials Testing, 54(11-12),1009-1014. 